\title{
Concrete Placement for Bridge Decks on an Expressway Extension Project
}

\author{
Janusz Hołowaty \\ Faculty of Civil Engineering and Architecture, West Pomeranian University of Technology, Szczecin 70-311, Poland
}

\begin{abstract}
The paper presents examples of technological designs for concrete placement in road bridges constructed during the S5/S10 expressway extension in Poland. The project included eight concrete or composite bridge structures with different numbers of decks. The concrete placement technology is presented for the following bridge decks: slabs cast-in-situ, composite with precast or VFT (prefabricated composite beam) beams and mixed with cast in situ slabs and VFT-WIB (filler beam) beams. Continuous concrete placement was adopted for almost all the bridge superstructures except the mixed-type decks where construction joints were necessary. To control shrinkage, formwork deformations and existing restraints, the concrete was poured in layers and in stages. The design pace of concrete placement was moderate to be regulated at site without compromising safety and quality. The placement methods enabled both efficient and safe concrete pours.
\end{abstract}

Key words: Concrete bridge, curing, fresh concrete, placement and consolidation, shrinkage.

\section{Introduction}

Concrete bridge construction requires the development of technologies for concrete placement. These should take into consideration a range of factors connected with the bridge's structural system, the required type of concrete and the capabilities of the contractors, in addition to such external parameters as ambient temperature and the environmental conditions during concrete placement. Many parameters influence the possibility that the concrete will crack during the early stages before attaining satisfactory strength for carrying strains and durability to external hazards [1-9].

In the paper, the concrete placement technologies adopted in the construction of bridge decks for the rebuilding of the S5/S10 expressway on the section between the Białe Błota and Stryszek (existing) interchanges in Poland are described (Fig. 1). The road section in question comprised the second phase of the Bydgoszcz southern bypass and forms a future

Corresponding author: Janusz Hołowaty, Ph.D., assistant professor, research fields: testing and design of bridges. E-mail: jah@wp.pl. part of the S5 and S10 expressways.

The concrete placement technologies for decks with five viaducts (WD) and three underbridges (PZ) (16 decks) are described. As a result of these technologies, solid mass concrete with no construction joints or with a limited number of such joints was obtained [6]. Different methods and directions for the concrete placement were adopted, taking into consideration the cast structure type, minimization of the influence of formwork and falsework deflections and a reduction of the effects of temperature on mass concrete in the expected environmental conditions.

\section{The Expressway and the Bridge Structures}

The project widened the existing single carriageway road to a dual carriageway expressway. It included two new carriageways for the main road, new distribution roads with sidewalks and the rerouting of a cycle lane, nine bridge structures, several culverts, retaining walls, road lighting and acoustic barriers. The total length of the main road is $12.4 \mathrm{~km}$ (Fig. 1). The concrete placement technology for decks of eight bridge structures is described in the paper. 


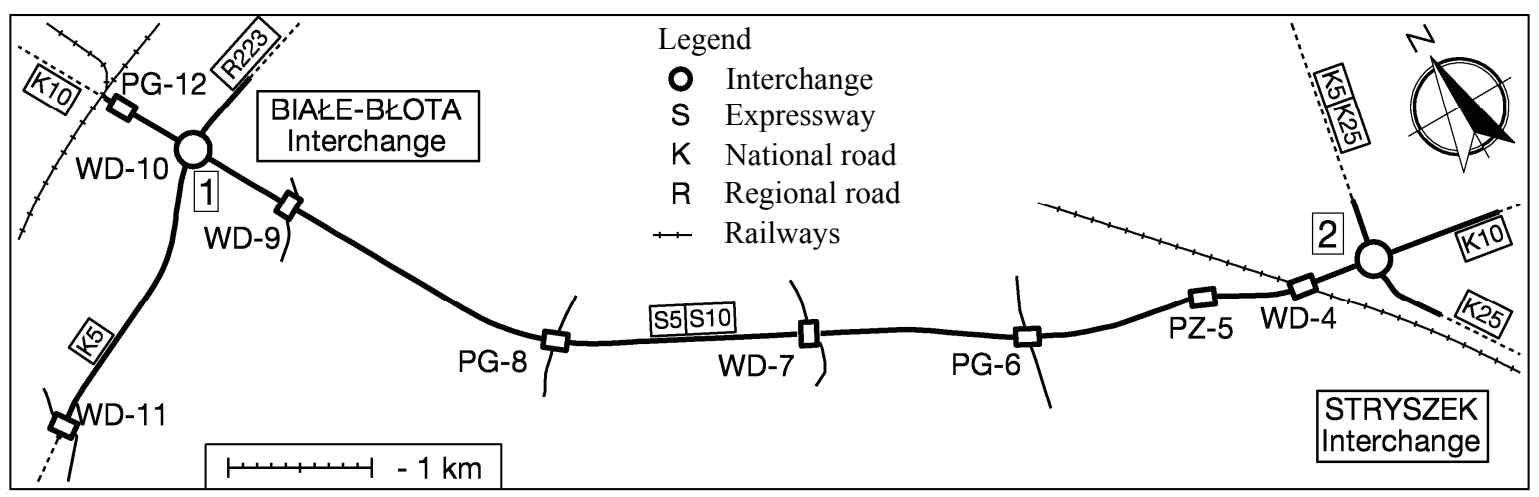

Fig. 1 Plan of S5/S10 road with nine bridge structures.

These bridges are of concrete or composite structures (Fig. 1). The WD-4 viaduct is along the S5/S10 expressway over a railway line, the WD-7 and WD-9 viaducts are over the S5/S10, the WD-10 viaduct is at the Białe Błota Interchange over the S10 and WD-11 viaduct is over the S5. In addition, there are three underbridges (technological crossings) of PG-6, PG-8 and PG-12 concrete frames and one wildlife crossing of PZ-5 steel folded plate.

The bridges are of different deck types. The WD-4 viaduct is a portal frame structure with prefab VFT-WIB beams and the WD-7 viaduct is two-span continuous structure with VFT beams. In the WD-9 viaduct, a four-span continuous composite concrete and in the WD-11 viaduct a two-span continuous composite concrete deck was developed with precast inverted $\mathrm{T}$ beams. Frame-reinforced concrete structures are also used for the WD-10 viaduct as three-span continuous slabs and for the underbridges (PG-6, PG-8 and PG-12) as one-span slabs. The number of superstructures in each bridge was adopted depending on the localization of a particular bridge and the number of through carriageways. In the WD-4 viaduct, three slab decks were developed and in the WD-10 viaduct four continuous slabs (the Białe Błota Interchange). For the rest of the overbridges, single decks were used. For the underbridges, separate decks for each carriageway were developed.

In the decks, structural concretes of strength classes C30/37 and C35/45 were accommodated. The concrete mixes were prepared using Portland cement
CEM I 42.5 HSR with flowing (0.39\%), air-entraining $(0.15 \%)$ and retarding $(0.15 \%)$ admixtures. The two mixes used $370 \mathrm{~kg}$ and $390 \mathrm{~kg}$ of cement, giving water/cement ratio $w / c=0.41$ and 0.39 , respectively. Sand $0 / 2$, granite aggregates $2 / 6$ and $6 / 16$ were used. Slump class was S3/S4 (a slump up to $150 \mathrm{~mm}$ ). To facilitate the supply of concrete mix and concrete placement, mixing trucks and concrete pumps were used. Pumpable concrete would be delivered from an industrial batch plant in Białe Błota. The continuous casting of large concrete pours by mobile concrete pumps is believed to facilitate and speed up repeated concrete works $[5,6]$.

All the bridge decks are typical slab structures or composite with concrete overlays on precast inverted $\mathrm{T}$ or VFT beams. The exception is the WD-4 viaduct over a railway line, where an untypical mix structure with VFT-WIB beams in the central section of the decks was developed. So the three slab decks of the frame structure for the WD-4 viaduct were constructed according to a special technology. The end parts of the decks near the abutments were constructed in reinforced concrete cast-in-situ and the central section of the decks was constructed as composite with precast VFT-WIB beams with concrete overlays. The end sections were cast on full falseworks with VFT-WIB beams supported on falseworks assembled along the railway line. All other in-situ decks were constructed in formwork supported by full falseworks. In the concrete or steel-concrete composite decks, the monolithic sections were cast on 
precast beams and on formwork supported by precast beams or members cast earlier. The bridge decks were cast from April to October 2009.

\section{General Requirements for Concrete Technology}

Both the mixing and placement of fresh concrete influence the final microstructure of structural concrete [1, 8]. Processes in fresh and hardening concrete have an enormous influence on the final strength and durability of the concrete. Unsuitable methods for the placement and compacting of concrete can cause a reduction in air content of the concrete, which can result in a lowering of the freezing and thawing resistance of concrete. Fresh concrete is a readily deformable material, but for obtaining the necessary strength and durability, important roles are played by the used mixing and placement methods. Fresh concrete can crack due to plastic shrinkage, plastic settlement and temperature differential between the exposed surface and the interior of the concrete. Early-age thermal cracking may occur because of early thermal contraction developed by thermal gradient from the heat of the cement hydration. Cracking in fresh concrete can be easily filled during the final finishing of the concrete surface, but these cracks may open again. Guidance and recommendations for checking and controlling cracking in bridge concrete members are given by Refs. [1, 2, 7]. However, predicting fresh concrete cracking or non-cracking is still considered to be a complex problem which is not clearly foreseen. To control and avoid cracking in the concrete, security and preventative measures should be undertaken. One such measure is planning and checking the mixing processes, as well as placing, consolidating and curing the fresh concrete.

For the mixes adopted in the project, concrete of strength classes C30/37 and C35/45 were used, and in addition to the foreseen casting periods, temperature changes and gradients were estimated for the cast decks according to CIRIA C660 guidance, using spreadsheet calculators included on the CD provided with the guide [2]. The guidance has already been adjusted to contemporary cements with a higher heat of hydration. The calculations take into account the expected minimum and maximum ambient temperature during placement of concrete for this region in Poland. The adiabatic rise of concrete temperature in a slab deck of $900-\mathrm{mm}$ depth for initial temperatures of casting equal to $10{ }^{\circ} \mathrm{C}$ and $25^{\circ} \mathrm{C}$, compared with a reference temperature of $20^{\circ} \mathrm{C}$ in the case of concrete class C35/40 with $390 \mathrm{~kg} / \mathrm{m}^{3}$ CEM I cement content, is shown in Fig. 2.

The initial casting temperature is set for the expected season of the concrete pours, e.g., spring/autumn and

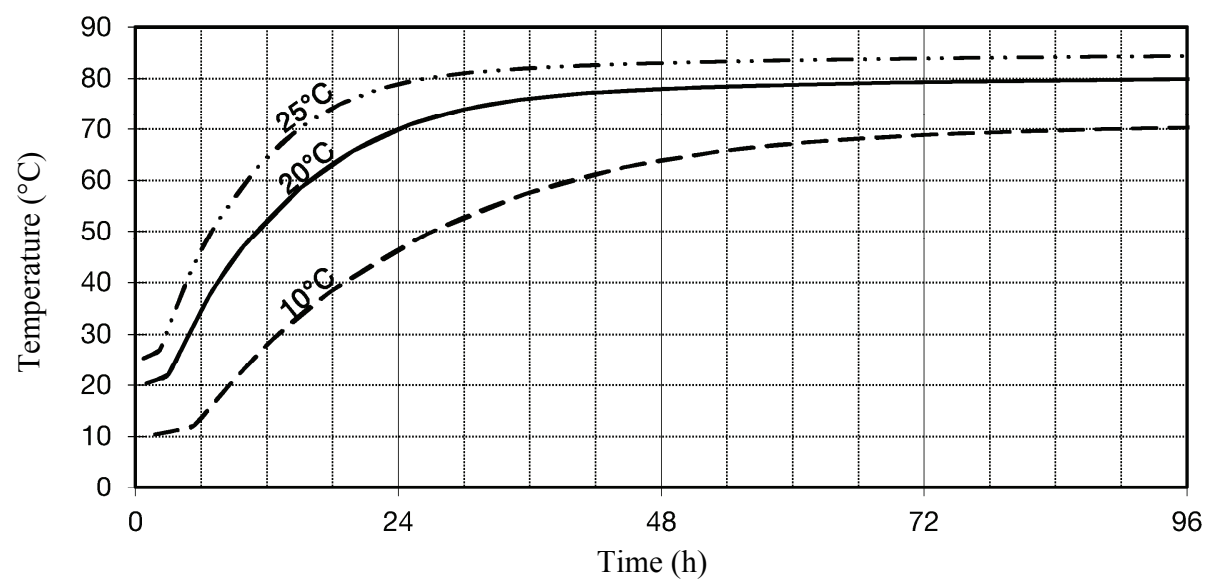

Fig. 2 Comparison of adiabatic temperature rise for concrete strength class $\mathbf{C 3 5 / 4 5}$ in different temperature placements for 900-mm depth slab deck. 


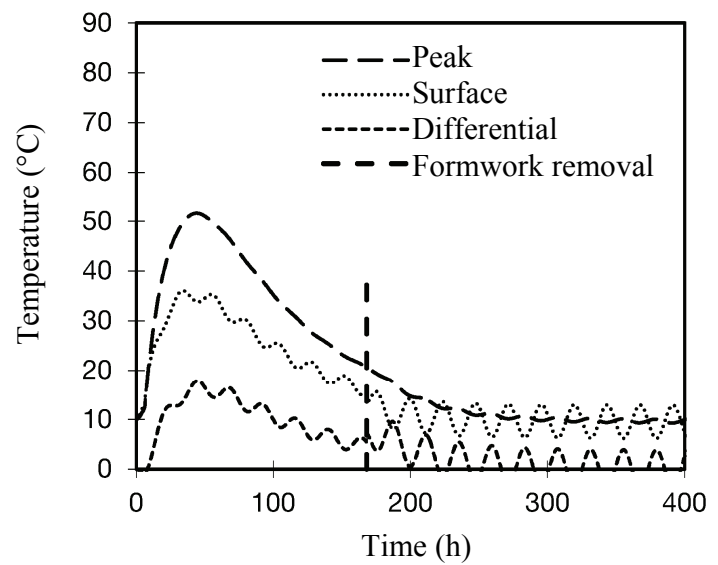

(a)

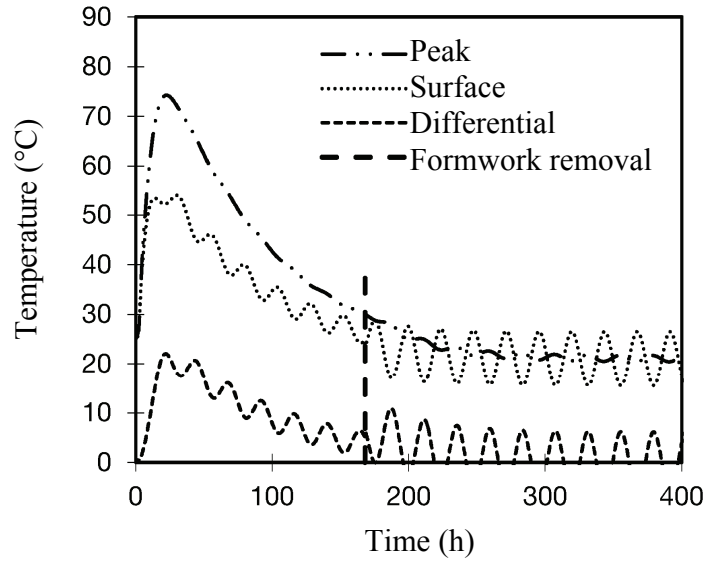

(b)

Fig. 3 Temperature rise and gradient changes in 900-mm depth slab deck for concrete strength class C35/45 under different conditions: (a) spring and autumn; (b) summer.

summer environmental conditions. The estimated temperature rise and gradient for the initial casting temperature are shown in Fig. $3 \mathrm{a}$ for $10^{\circ} \mathrm{C}$ and in Fig. $3 \mathrm{~b}$ for $25^{\circ} \mathrm{C}$ initial temperature. The calculations develop the spreadsheet calculator [2]. The results of temperature changes are for the exposed concrete surface and interior of concrete with formwork removal at seven days $(168 \mathrm{~h})$. The temperature drop in the concrete is $T_{1}=42{ }^{\circ} \mathrm{C}$ for the spring/autumn condition of concrete placement $\left(10{ }^{\circ} \mathrm{C}\right)$ and $T_{1}=54{ }^{\circ} \mathrm{C}$ in summer placement $\left(25^{\circ} \mathrm{C}\right)$. For thinner members and in overlays, the thermal gradients and temperature falls are smaller. As a factor for avoiding concrete surface cracking, the minimum reinforcement ratio requirement for a given crack width was checked in the deck sections. In all the bridge decks, the requirement was satisfied for a 0.3-mm nominal crack width. To minimize shrinkage and falsework deflection along with internal and external restraints, an appropriate sequence of layers and configuration with a limited number of construction joints were adopted for the concrete placement in bridge decks.

\section{Technology of concrete placement}

The concrete placement methods adopted are shown in Figs. 4-9, for the PG structures, WD-4, WD-7, WD-9 and WD-10 viaducts, respectively. For the other bridge decks, the typical continuous placement was adopted, changing the sequence of concrete layers near the supports to reduce the influence of falsework deflection. While casting, a 350-mm maximum layer thickness was used, exceptionally $400-\mathrm{mm}$. Layers of such a thickness are readily compacted. The conditions of concrete supply and placement were determined to avoid separation of the aggregate and a reduction in the air content of the concrete. Consolidation of the concrete was planned with layers by internal vibrators and the previously cast layers were re-vibrated at a depth of at least $100 \mathrm{~mm}$. In each bridge deck, a plan for the vibrating layers was drawn up. Timetables for concrete supply were drawn up for moderate concrete pour speed. In all the concrete layers and segments, the adopted pour speed enabled the casting of fresh concrete onto fresh concrete.

Continuous concrete placement in one direction enabled the successive movement of equipment and workers along the decks without the necessity for retreating and return stations. The upper surfaces of the decks were finished with design falls (Figs. 4-11). The top surfaces were covered with a paraffin membrane to protect the fresh concrete from moisture loss and possible rainfall. In summer conditions with a temperature higher than $27{ }^{\circ} \mathrm{C}$, additional water spraying after casting was advised. 

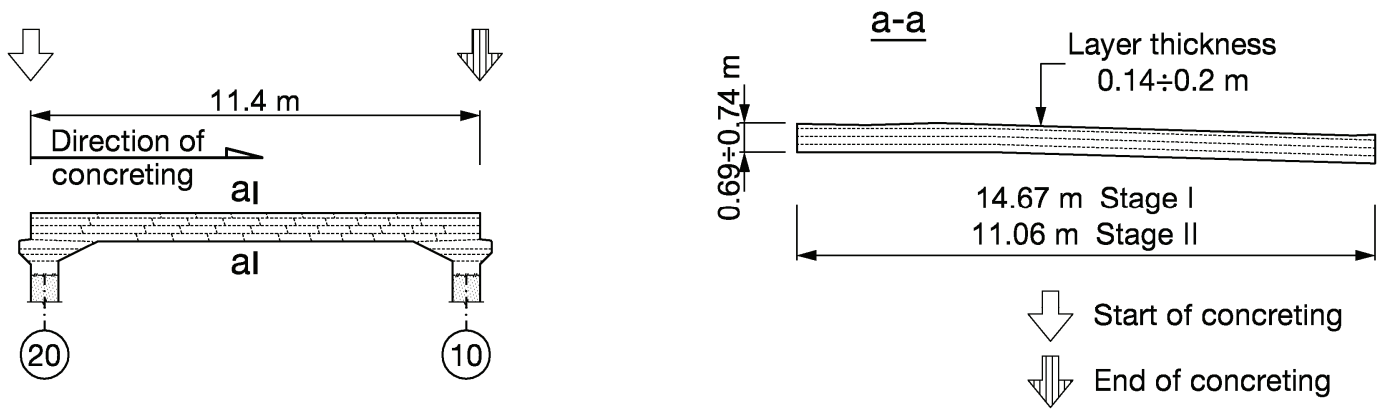

Fig. 4 Scheme for concrete placement in slab decks of PG crossings.

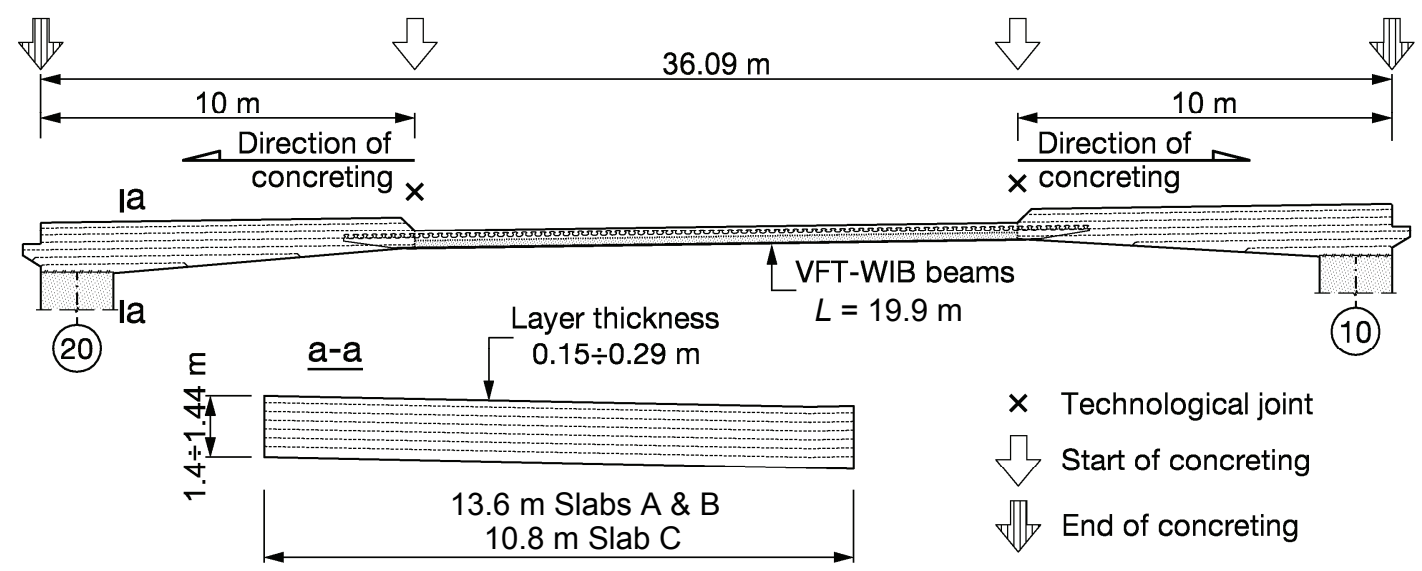

(a)

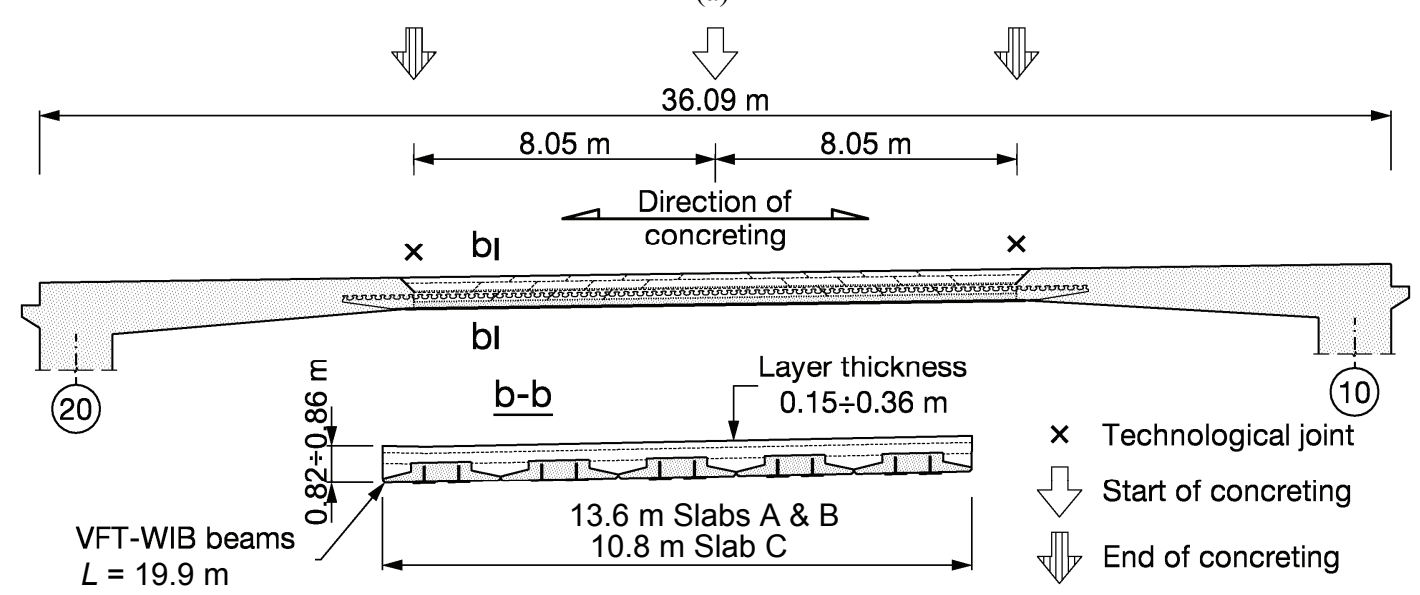

(b)

Fig. 5 Scheme for concrete placement in slab decks of WD-4 viaduct (A, B and C slabs): (a) Stage I-casting of span support sections; (b) Stage II-casting of overlay on precast beams.

In all the bridge decks except for the WD-4 viaduct, there were no vertical construction joints. In the frame or continuous superstructures, technological joints were developed only between a slab deck and supports or cross beams. Cast-in-situ decks or overlays on precast beams were continuously cast in layers of one on another. Concrete was cast from one support to the next support, changing only the sequence of layer placement near the intermediate supports-after casting the support segment, a top layer of concrete was cast over a pier.

The slab decks of the WD-4 viaduct over a railway line were constructed using precast VFT-WIB beams directly over the tracks (Figs. 12 and 13). The design 
sequence for construction introduced vertical construction joints between the concrete overlay on the precast beams and the in-situ section of the spans.

During the first stage, abutment sections of the spans were cast in situ on full falsework. In the second stage, the concrete overlay on prefabs was cast (Fig. 13). An aerial view of the cast slabs for the WD-10 viaduct at the Białe Błota Interchange is shown in Fig. 14.

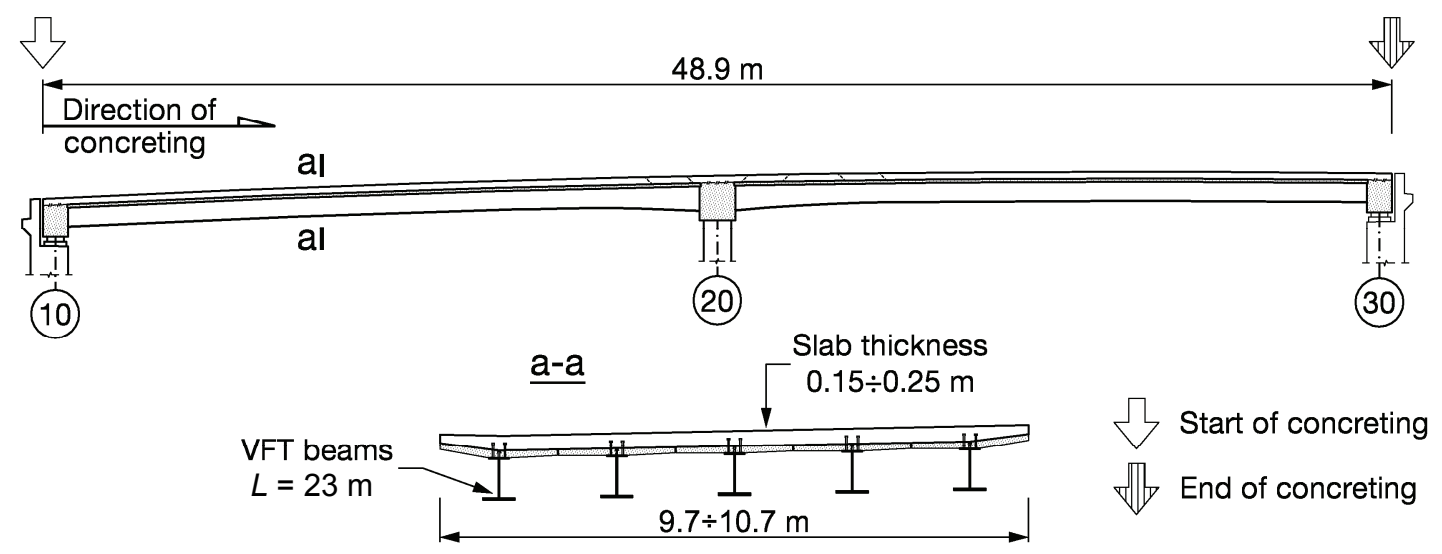

Fig. 6 Scheme for concrete overlay placement in WD-7 viaduct deck.

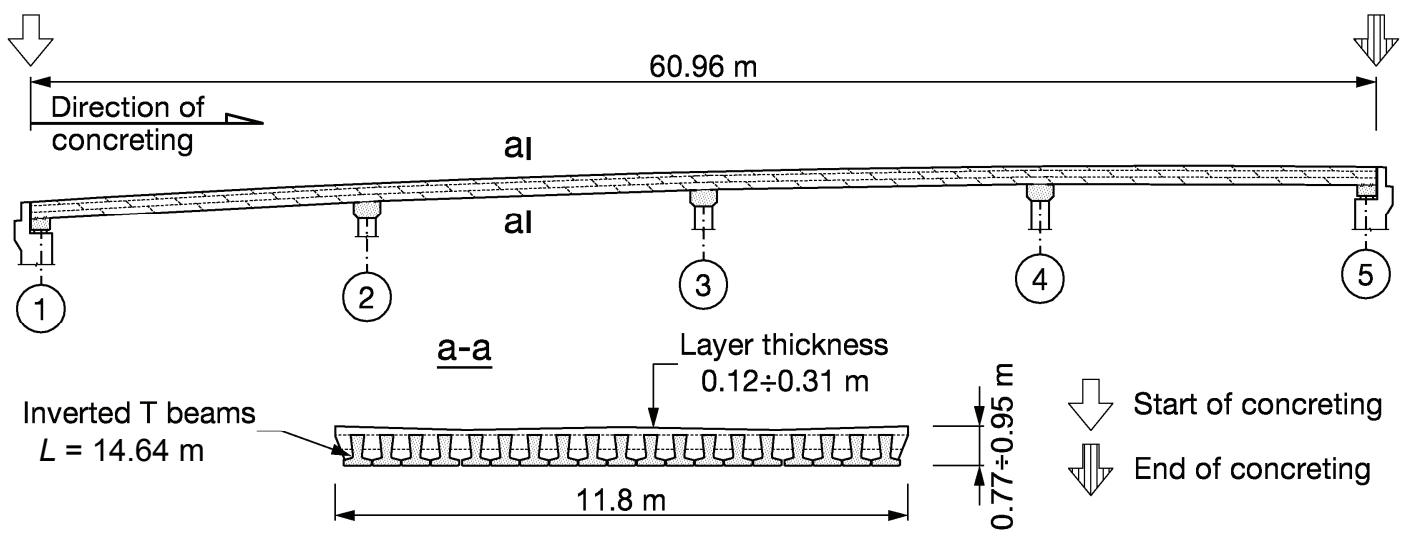

Fig. 7 Scheme for concrete overlay placement in WD-9 viaduct deck.

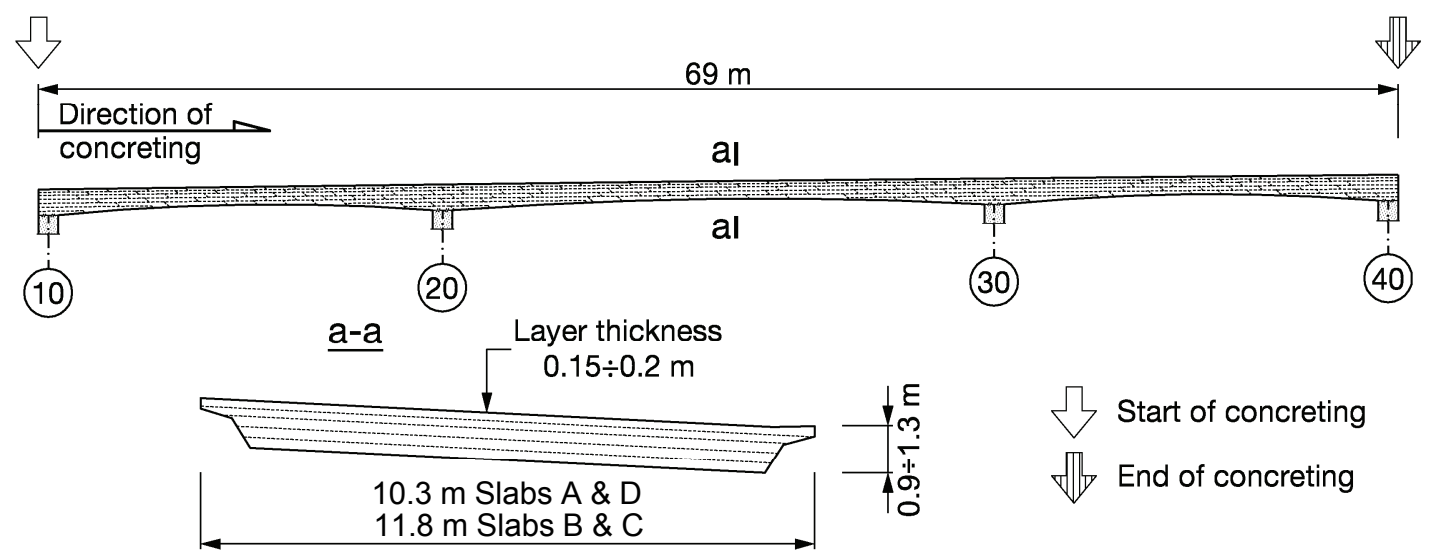

Fig. 8 Scheme for concrete placement in slab decks of WD-10 viaduct (A, B, C and D slabs). 


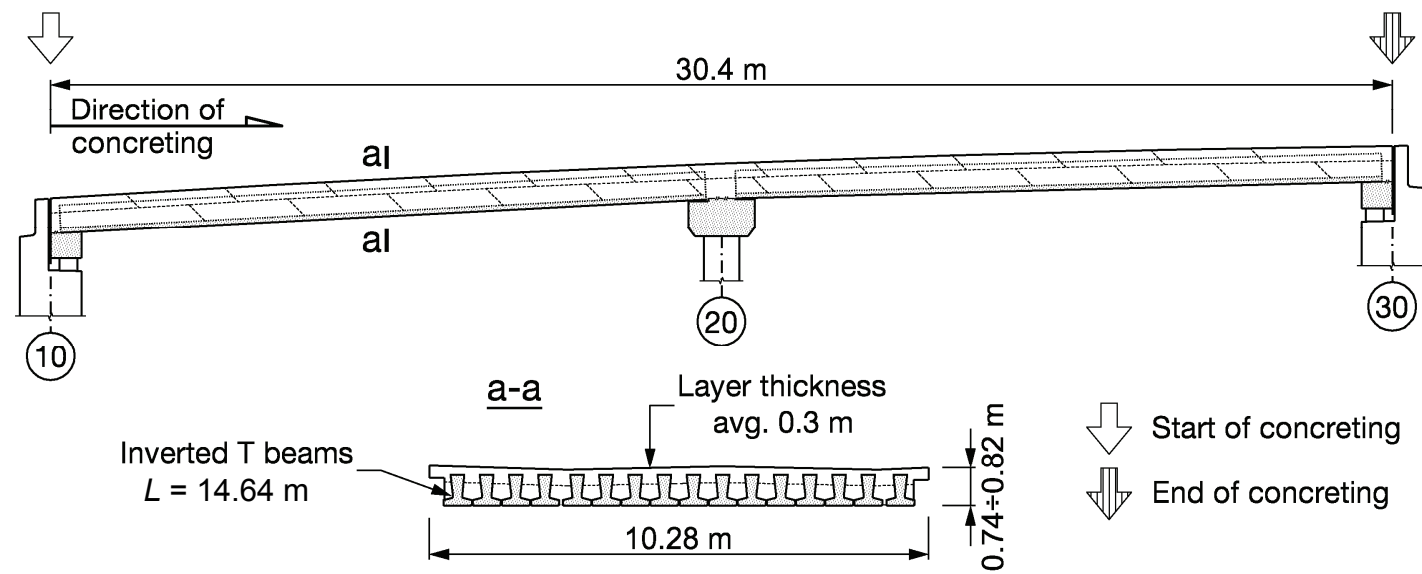

Fig. 9 Scheme for concrete overlay placement in WD-11 viaduct deck.

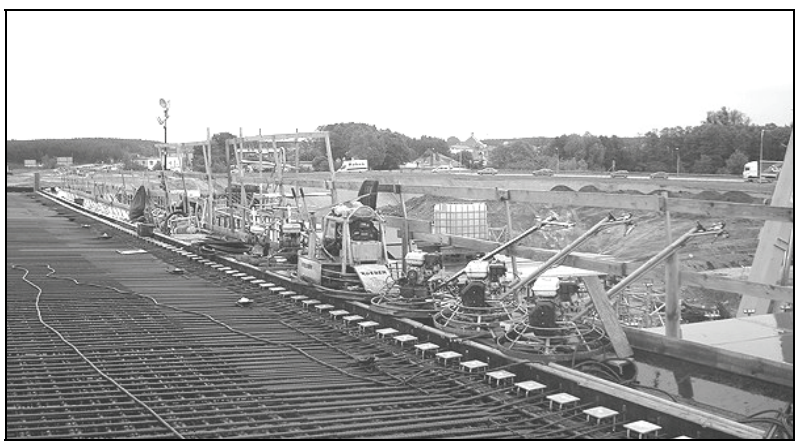

Fig. 10 Equipment for concrete surface finishing.

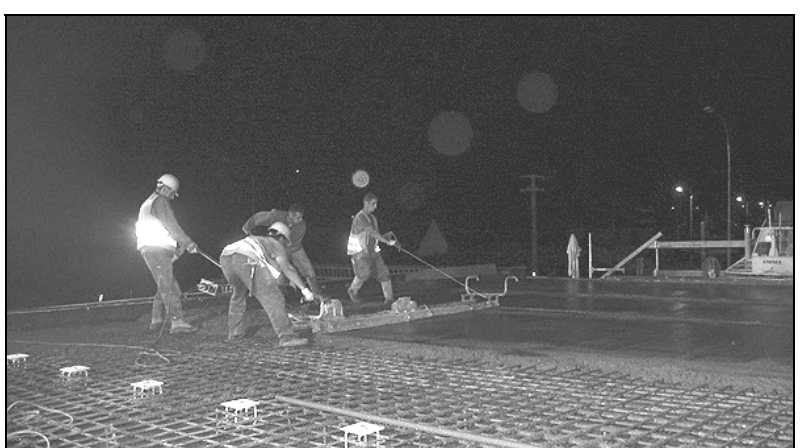

Fig. 11 Concrete placement for PG-8 slab.

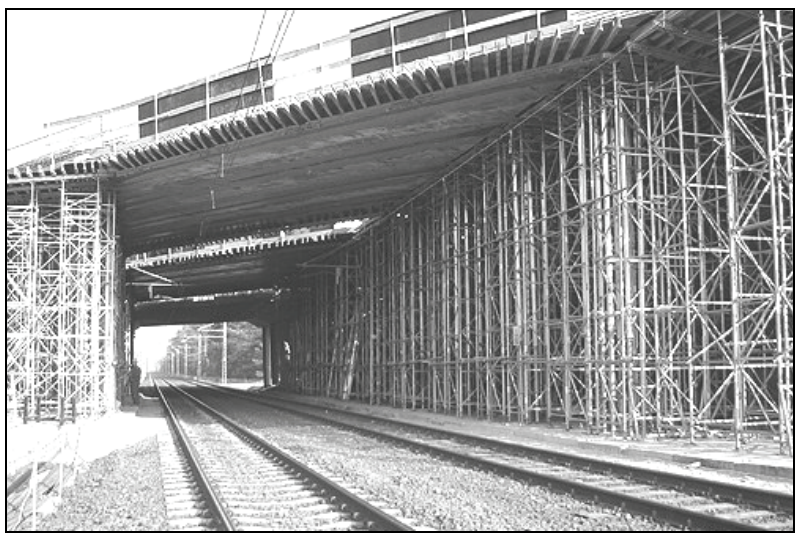

Fig. 12 View of falsework for WD-4 viaduct.

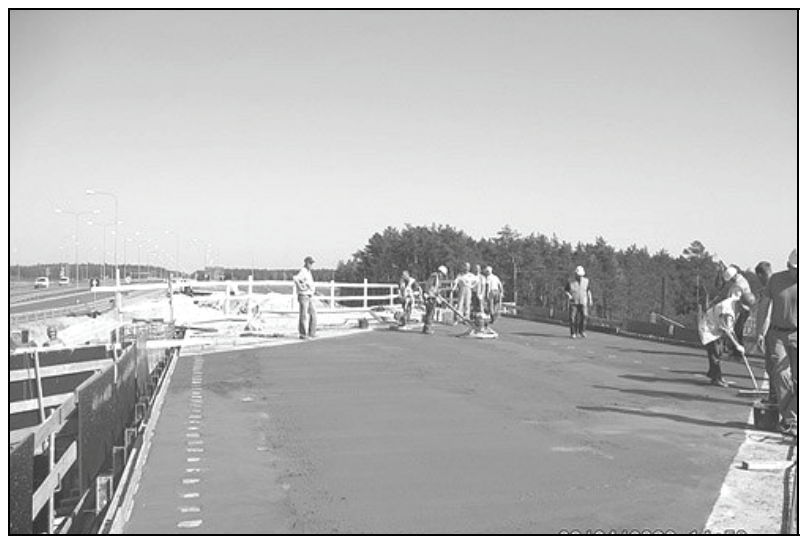

Fig. 13 Concrete finishing for WD-4 C slab.

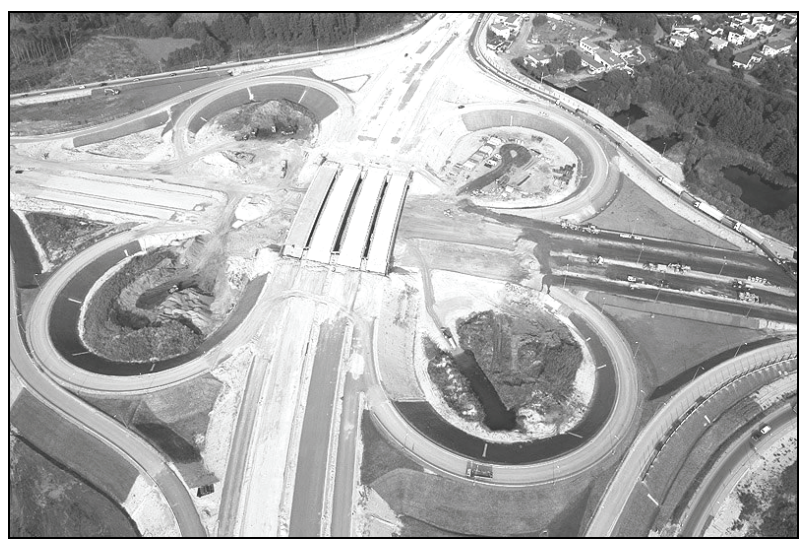

Fig. 14 View of WD-10 viaduct and Biale Błota Interchange after casting of four slab decks.

\section{Conclusions}

The adopted concrete placement technology included several general aspects which were obeyed in the design of concrete pours:

- assessment of the ambient temperature and the temperature rise and gradients in the mature concretes 
in the expected period of concrete placement;

- checking the amount and distribution of surface reinforcement which should ensure crack limits;

- assuming the method of concrete transportation, placement and curing (rather long);

- planning continuous concrete pours and avoiding technological joints where possible;

- use of concrete layer thickness and speed of concrete placement that allow proper compaction;

- avoiding non-uniform deflection of formwork.

The adopted technology of concrete placement in bridge decks enables the efficient and safe casting and consolidation of structural concrete. The 16 bridge decks were constructed using continuous or staged casting. The developed technology for concrete placement took into account continuous concrete placement or with a minimal number of construction joints. Concrete technology designs were drawn up separately for each bridge deck in each construction stage. Early thermal and shrinkage effects in fresh concrete, as well as the minimal ratio of reinforcement, were estimated in compliance with international and national requirements.

Concrete technology designs were drawn up in advance to enable their acceptance, planning and corrections in concrete supplies in addition to the organization of the relevant amount of equipment and workers required for concrete works.

\section{References}

[1] fib (fédération internationale du béton). 2006. fib Bulletin 51, Structural Concrete. Textbook on behaviour, design and performance, $f i b$, Lausanne, Switzerland.

[2] Bamforth, P. B. 2007. Early-Age Thermal Crack Control in Concrete. C660. London: CIRIA (Construction Industry Research and Information Association).

[3] HMSO (Her Majesty's Stationary Office). 1987. "Early Thermal Cracking of Concrete." In Design Manual for Roads and Bridges. BA24/87 (Advice Note), BD 28/87 (Departmental Standard). London: Department of Transport, Highways and Traffic, HMSO.

[4] Bussell, M. N., Carher, R. 1995. Design and Construction of Joints in Concrete Structures. Report 146, CIRIA, London, Great Britain.

[5] Cooke, T. H. 1990. Concrete Pumping and Spraying. A Practical Guide. London: Thomas Telford.

[6] Hołowaty, J. 2013. "Technology of Concrete Placement in Bridge Decks for S5/S10 Expressway Extension." In Proceedings of fib Symposium on Engineering a Concrete Future: Technology, Modeling \& Construction, IACIE (Israeli Association of Construction \& Infrastructure Engineers) and Faculty of Civil and Environmental Engineering, Technion-Israel Institute of Technology, 439-42.

[7] Flaga, K. 2004. Shrinkage Stresses and Reinforcement in Concrete Structures. Monografia No. 295. Kraków University of Technology, Kraków, Poland. (in Polish)

[8] MEMOAR (Mémento pour la mise en oeuvre sur ouvrages d'art). 2007. Guide for Construction on Bridges. Bagneux Cedex: Sétra (Technical Department for Transport, Roads and Bridge Engineering and Road Safety).

[9] Neville, A. M. 2012. Properties of Concrete. Kraków: Polish Cement Association. (in Polish) 